\title{
A prospective randomized comparison of left and right radial approach for percutaneous coronary angiography in Asian populations
}

This article was published in the following Dove Press journal:

Clinical Interventions in Aging

20 June 2014

Number of times this article has been viewed

\section{Hongyu $\mathrm{Hu}$ \\ Qiang Fu \\ Wei Chen \\ Dezhao Wang \\ Xu Hua \\ Buxing Chen}

Department of Cardiology, Beijing Tiantan Hospital, Capital Medical University, Beijing, People's Republic of China
Correspondence: Buxing Chen Department of Cardiology, Beijing Tiantan Hospital, Capital Medical University, No 6 Tiantanxili, Dongcheng District, Beijing, People's Republic of China

Tel +861067096572

Fax +86I067096572

Email chbux@I26.com
Background: The efficacy of coronary angiography may be different in the right radial approach (RRA) and the left radial approach (LRA) due to more common vascular tortuosity in the RRA. The aim of the study was to determine whether LRA is a valid alternative for coronary angiography compared with RRA in Asian populations.

Methods: This is a single-center, prospective, randomized controlled study. A total of 1,400 consecutive patients undergoing diagnostic coronary angiography were recruited and randomized to the RRA (number $[n]=700)$ or LRA $(n=700)$ group. The primary end point was total procedural duration. Secondary end points included fluoroscopy time, dose of radiation including cumulative air kerma and dose area product, contrast volume, and the incidence of vascular complications.

Results: Coronary procedural success was achieved in 682 of $700(97.4 \%)$ patients in the RRA and 680 of $700(97.1 \%)$ in the LRA. The total procedural time (RRA 14.1 \pm 6.3 minutes versus LRA 13.2 \pm 6.0 minutes; $P=0.006$ ) and fluoroscopy time (RRA 3.8 \pm 3.3 minutes versus LRA $3.4 \pm 2.8$ minutes; $P=0.046$ ) were significantly shorter via LRA in comparison to RRA. The percentage of hydrophilic wire use was also lower in the LRA group (14\% [RRA] versus $10 \%$ [LRA]; $P=0.016)$. The dose of radiation and contrast volume were not different between the two approaches. No cases of major bleeding and vascular complications requiring surgical intervention were reported, other than with one patient who experienced a symptomatic stroke and died in the RRA group compared with none in the LRA group.

Conclusion: The LRA seems to be a feasible alternative for coronary angiography in Asian patients due to shorter procedural duration and fluoroscopy time, as well as less hydrophilic wire use in comparison to RRA.

Keywords: left radial approach, right radial approach, coronary angiography

\section{Introduction}

Previous studies have shown that transradial cardiac catheterization has decreased not only bleeding complications related to the access site, as well as procedural discomfort, but also morbidity and hospitalization rates as compared to the transfemoral approach. ${ }^{1-8}$ At present, the right radial approach (RRA) has become the first choice for the performance of routine coronary angiography and interventions for comfort reasons in daily clinical practice despite more marked subclavian artery tortuosity. ${ }^{9}$ Although the left radial approach (LRA) may reduce fluoroscopy time and cerebrovascular complications compared with RRA, ${ }^{10-12}$ several studies have also obtained conflicting results. ${ }^{13-16}$ Additionally, most of the investigations evaluating the efficacy of the transradial approach have been conducted among Caucasian persons. There may be differences in cardiac catheterization between Western and Asian patients 
owing to their different races and body sizes. To date, it remains unclear whether LRA offers more significant clinical advantages to patients undergoing coronary angiography than RRA in real-world practice, and few data from randomized controlled trials in Asian patients are available.

Therefore, the aim of this study was to randomly investigate and compare the feasibility and safety of LRA compared with RRA for coronary angiography in Chinese patients.

\section{Materials and methods Study population}

Consecutive patients undergoing coronary diagnostic angiography were recruited between March 2011 and November 2013. Patients of 20 years of age and older, and who were able to provide informed consent, were included in the study. Exclusion criteria included acute ST-elevation myocardial infarction, a previous transradial coronary procedure, previous coronary artery bypass graft surgery, and hemodynamic instability. Included patients were divided randomly into either the LRA or RRA group on the basis of the randomization list. The randomization list was managed by a staff member who informed the operator just before coronary procedure. Coronary angiography was performed by four experienced operators who independently completed transradial coronary angiography at least 200 .

This study was designed and carried out in accordance with the principles of the Declaration of Helsinki, and approved by the ethics committee of Beijing Tiantan Hospital (Beijing, People's Republic of China). All patients provided written informed consent.

\section{Transradial cardiac catheterization}

Regardless of LRA or RRA, all coronary procedures were performed on the right side of the patient. The wrist of all patients was hyperextended and rotated, as per the supine position, and secured to an armrest.

After receiving local anesthesia with $1 \%$ lidocaine, access to the wrist was obtained using the Seldinger technique with a $20 \mathrm{G}$ needle, and a 6 French radial sheath was inserted. Lowmolecular-weight heparin $(0.4-0.6 \mathrm{~mL})$ was administered after sheath insertion, with doses varying according to the weight of the patients. Antispasm medications were not routinely used, and in case of radial spasm, nitroglycerine $200 \mu \mathrm{g}$ was administered via radial sheath. A standard 0.035 inch J-tip wire (Cordis Corporation, Bridgewater Township, NJ, USA) was applied to lead the catheter to the aortic sinus cusp.

Catheter choice was left to the operator's discretion. Initially, a Judkins left 3.5 or 4 catheter (Cordis Corporation) for the left coronary artery, and a Judkins right 3.5 or 4 catheter (Cordis Corporation) for the right coronary artery was used. In the event that the Judkins catheters were unable to engage the coronary ostia, the operator changed them to different curve catheters, such as the Amplatz left 1 or right 1 (Cordis Corporation), or to the Tiger 4.0 (radial TIG, Terumo Corporation, Tokyo, Japan). Catheter exchange was conducted using a 0.035 inch guide wire.

After coronary angiography, the arterial sheath was removed immediately. An inflatable wrist band (TR Band ${ }^{\mathrm{TM}}$; Terumo Corporation) was applied for hemostasis.

\section{Definitions and end points}

Procedure failure was considered as it being impossible to completely carry out coronary angiography using the access point of choice and the need to shift to the opposite approach. Radial cannulation time was defined as the time from the application of local anesthesia to arterial sheath insertion. Coronary time was defined as the time from radial sheath insertion to the first cineangiography recording. Time to diagnosis was considered as the time from the first cineangiography recording to the end of the procedure. Total procedure time was calculated from the time of radial cannulation to the end of the procedure. All procedure times are expressed in minutes.

The primary end point was total procedural duration. The secondary end points were fluoroscopy time, dose of radiation including cumulative air kerma (CAK), CAK dose area product (CAK DAP), contrast volume, and the incidence of vascular complications.

\section{Statistical analysis}

Variables were analyzed for a normal distribution with the Kolmogorov-Smirnov test. Continuous variables following a normal distribution were expressed as the mean \pm standard deviation, and those not normally distributed were indicated as the median with interquartile range. Categorical variables were expressed as frequencies and percentages. Differences between the two groups were determined using Student's $t$-test or the Mann-Whitney $U$-test, as appropriate, for continuous variables. The $\chi^{2}$ test or Fisher's exact test were used as appropriate to compare categorical variables. The sample size was estimated on the basis of procedure time according to our previous experience. To detect a difference of $1.0 \pm 6.5$ minutes in procedure time with a power of 0.8 and an $\alpha$ error of 0.05 , the number of patients required was calculated to be at least 1,330 patients in all (665 patients in each group). Differences were considered significant at $P<0.05$. Statistical analysis was performed with SPSS 17.0 software (IBM Corporation, Armonk, NY, USA). 


\section{Results}

A total of 1,400 patients were consecutively enrolled and randomized to either the RRA (number $[n]=700$ ) or LRA group $(n=700)$. Of these, 1,362 patients underwent coronary angiography successfully (see Figure 1 for a flow diagram of this study). The baseline clinical characteristics of the patients (summarized in Table 1) were similar in the RRA and LRA groups.

The coronary procedural success rate was not different between the two approaches (RRA, 97.4\% versus LRA, 97.1\%; $P=0.74$ ). Procedural failure was observed in 18 patients using the RRA and in 20 patients using the LRA. The reasons for procedure failures were related to access failure (eight in RRA and 15 in LRA) and severe tortuosity of the brachial or subclavian artery (ten in RRA and five in LRA). Crossover to the contralateral radial approach was first conducted after procedure failure occurred. In the event that the contralateral radial approach was not a success, a transfemoral approach was ultimately selected. In the study, crossover to the contralateral radial artery was noted in most cases of procedure failure from both groups. Crossover from the radial to femoral artery is rare, and there were no differences between the RRA and LRA groups (one case versus one case, respectively).

The details of the catheters used are depicted in Table 2. The total procedure time (RRA, 14.1 \pm 6.3 minutes versus
LRA, $13.2 \pm 6.0$ minutes; $P=0.006$ ), coronary time (RRA, 1.9 [1.4, 3.0] minutes versus LRA, 1.7 [1.2, 2.9] minutes; $P=0.001)$ and fluoroscopy time (RRA, 3.8 \pm 3.3 minutes versus LRA, $3.4 \pm 2.8$ minutes; $P=0.046$ ) were significantly shorter via the LRA in comparison to the RRA. Moreover, the percentage of hydrophilic wire use was lower in the LRA group than in the RRA group (RRA, 14\%; LRA, 10\%; $P=0.016)$. The dose of radiation (CAK: RRA, 320 $\pm 205 \mathrm{mGy}$ versus LRA, $302 \pm 173 \mathrm{mGy}, P=0.09$; CAK DAP: $28 \pm 20$ $\mathrm{Gycm}^{2}$ versus $\left.26 \pm 17 \mathrm{Gycm}^{2}, P=0.13\right)$ and contrast volume (RRA, $63 \pm 14 \mathrm{~mL}$ versus LRA $62 \pm 17 \mathrm{~mL} ; P=0.29$ ) were not different between the two approaches (Table 3 ).

Vascular complications are summarized in Table 4. One patient in the RRA group experienced a symptomatic stroke and died; the patient even underwent cerebrovascular interventional thrombolytic therapy in the RRA group. This was not noted in the LRA group. The incidences of radial artery spasm, loss of radial artery pulse, puncture site bleeding, and development of a forearm hematoma were not different between both approaches. Also, no pseudoaneurysms or arteriovenous fistulas requiring surgical intervention were reported.

\section{Discussion}

The major finding of the present study is that the LRA and RRA are equally effective and feasible for coronary angiography.

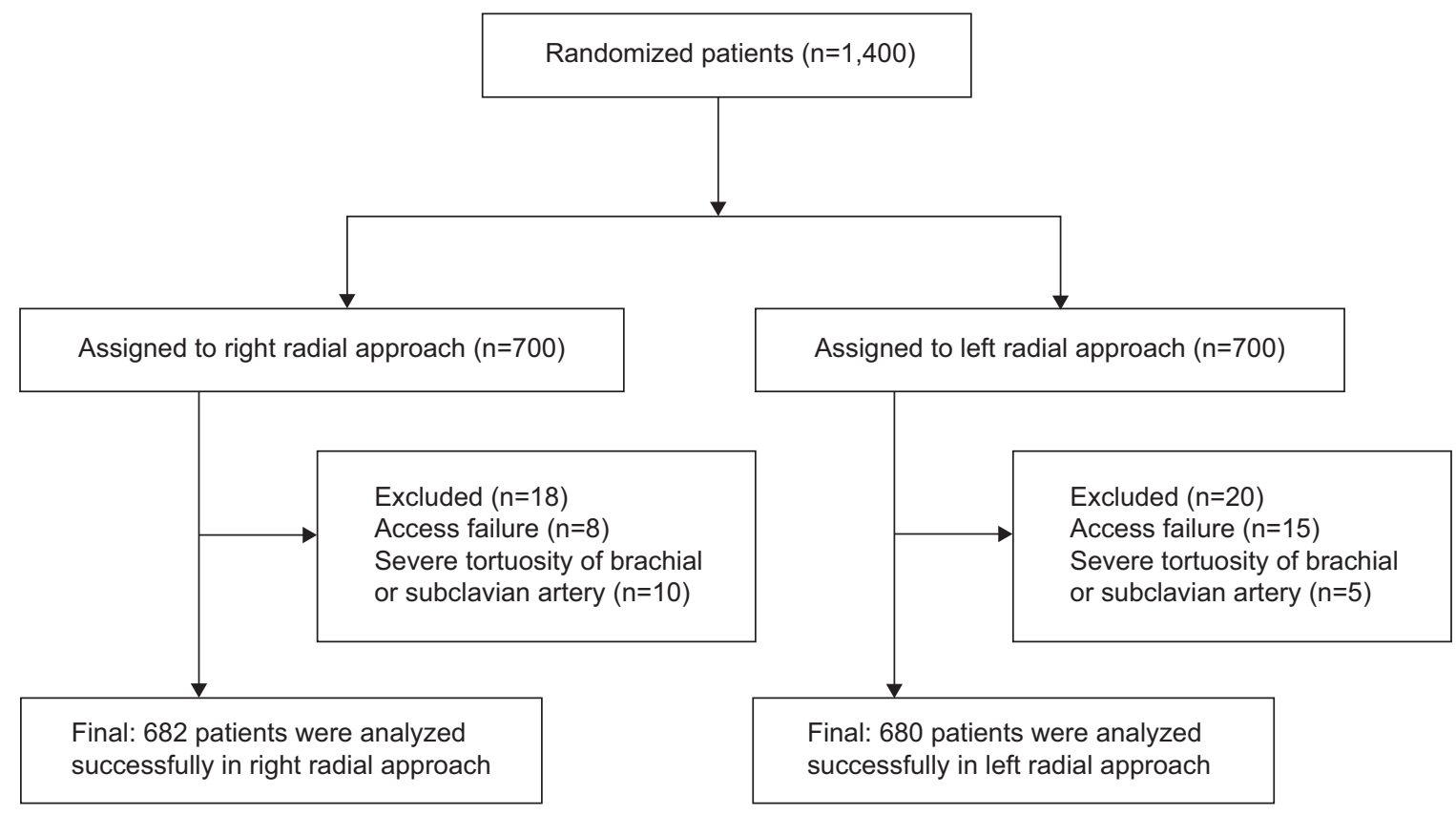

Figure I Flow diagram of the study.

Notes: Comparison between the left and right radial approaches for coronary angiography. In I,362 of the I,400 randomized patients, a coronary angiography was performed successfully. Abbreviation: $n$, number. 
Table I Baseline characteristics

\begin{tabular}{|c|c|c|c|}
\hline & $\begin{array}{l}\text { RRA } \\
(n=700)\end{array}$ & $\begin{array}{l}\text { LRA } \\
(n=700)\end{array}$ & $P$-value \\
\hline Age (years) & $62 \pm 10$ & $61 \pm 10$ & 0.71 \\
\hline Male & $419(60 \%)$ & $40 \mathrm{I}(57 \%)$ & 0.33 \\
\hline Height (cm) & $165 \pm 8$ & $165 \pm 8$ & 0.67 \\
\hline Weight (kg) & $71 \pm 12$ & $70 \pm 11$ & 0.64 \\
\hline BMI $\left(\mathrm{kg} / \mathrm{m}^{2}\right)$ & $25.7 \pm 4.2$ & $25.7 \pm 3.6$ & 0.89 \\
\hline Creatinine $(\mu \mathrm{mmol} / \mathrm{L})$ & $65.8 \pm 15.8$ & $66.5 \pm 18.0$ & 0.61 \\
\hline Hypertension & $473(68 \%)$ & $464(66 \%)$ & 0.61 \\
\hline Diabetes mellitus & 197 (28\%) & 197 (28\%) & 1.00 \\
\hline Dyslipidemia & $320(46 \%)$ & $311(44 \%)$ & 0.63 \\
\hline Currently smoking & $249(36 \%)$ & $235(34 \%)$ & 0.43 \\
\hline
\end{tabular}

Note: Data are expressed as the mean \pm standard deviation or number (\%).

Abbreviations: RRA, right radial approach; $n$, number; LRA, left radial approach; BMI, body mass index.

However, the LRA is associated with significantly shorter total procedure durations, fluoroscopy times, and requires less hydrophilic wire use in comparison to the RRA.

The transradial approach offers significant advantages over the transfemoral approach, and it has become a safe and viable approach for cardiac catheterization. Thus, the feasibility and efficacy of LRA and RRA have been compared in recent years; however, the results have been conflicting. ${ }^{13-16}$ Several studies showed significantly shorter fluoroscopy times and fewer cerebrovascular complications with the LRA, as explained by the higher incidence of radial loops and subclavian tortuosity with the RRA, ${ }^{13,15}$ whereas other observations revealed no significant difference between the LRA and RRA in terms of procedural success rate, procedural duration, contrast dose, or the number of catheters used to complete the procedure. ${ }^{16,17}$

In the present study, the rate of procedural success was substantial at $97 \%$, and was similar between the left and right approaches. Radial access failure and tortuosity of the radial-brachial-subclavian-innominate artery axis were the major reasons for coronary procedure failure. Our study

Table 2 The details of the catheter used

\begin{tabular}{lll}
\hline & $\begin{array}{l}\text { RRA } \\
(\mathbf{n = 6 8 2})\end{array}$ & $\begin{array}{l}\text { LRA } \\
(\mathbf{n = 6 8 0 )}\end{array}$ \\
\hline Judkins R 3.5, 5 F & 623 & 658 \\
Judkins L 3.5, 5 F & 627 & 657 \\
Judkins R 4.0, 5 F & 57 & 27 \\
Judkins L 4.0, 5 F & 66 & 45 \\
Judkins L 5.0, 5 F & $\mathrm{I}$ & $\mathrm{I}$ \\
Amplatz R I, 5 F & 6 & 14 \\
Amplatz L I, 5 F & 9 & $\mathrm{II}$ \\
Radial TIG, 5 F & 44 & 35 \\
\hline
\end{tabular}

Notes: Judkins (Cordis Corporation, Bridgewater Township, NJ, USA); Amplatz (Cordis Corporation); Radial TIG (Terumo Corporation, Tokyo, Japan).

Abbreviations: RRA, right radial approach; $\mathrm{n}$, number; LRA, left radial approach; $R$, right; F, French; L, left; TIG, Tiger.
Table 3 Procedural characteristics of coronary angiography

\begin{tabular}{llll}
\hline & $\begin{array}{l}\text { RRA } \\
(\mathbf{n}=682)\end{array}$ & $\begin{array}{l}\text { LRA } \\
(\mathbf{n}=680)\end{array}$ & P-value \\
\hline Radial cannulation time (minutes) & $3.5 \pm 2.8$ & $3.2 \pm 2.4$ & 0.10 \\
Coronary time (minutes)* & $1.9(1.4,3.0)$ & $1.7(1.2,2.9)$ & $0.00 \mathrm{I}$ \\
Time to diagnosis (minutes) & $5.8 \pm 3.4$ & $5.6 \pm 3.4$ & 0.27 \\
Total procedural time (minutes) & $14.1 \pm 6.3$ & $13.2 \pm 6.0$ & 0.006 \\
CAK (mGy) & $320 \pm 205$ & $302 \pm 173$ & 0.09 \\
CAK DAP (Gycm $\left.{ }^{2}\right)$ & $28 \pm 20$ & $26 \pm 17$ & 0.13 \\
Fluoroscopy time (minutes) & $3.8 \pm 3.3$ & $3.4 \pm 2.8$ & 0.046 \\
Contrast volume (mL) & $63 \pm 14$ & $62 \pm 17$ & 0.29 \\
Hydrophilic wire use & $96(14 \%)$ & $67(10 \%)$ & 0.016 \\
Number of catheters & $2.1 \pm 0.4$ & $2.1 \pm 0.4$ & 0.69 \\
\hline
\end{tabular}

Note: Data are expressed as the mean \pm standard deviation, or *median (25th percentile and 75 th percentile), or number (\%).

Abbreviations: RRA, right radial approach; $n$, number; LRA, left radial approach; CAK, cumulative air kerma; CAK DAP, cumulative air kerma dose area product.

demonstrated that the LRA was associated with shorter total procedure duration, coronary time, and fluoroscopy time when compared with the RRA. Our findings are in accordance with those by Sciahbasi et $\mathrm{al}^{11}$ and possible explanations for this include: 1) there are certain anatomical differences between the two routes of access. The LRA has lower subclavian tortuosity and permits more direct access to the ascending aorta (as is the case with femoral access), whereas the RRA may be more difficult to access, owing to its tortuosity and to the atherosclerosis of the right common brachiocephalic trunk and subclavian artery; 2) Catheter manipulation is easier in the LRA because the LRA allows for quicker and more direct access to the left coronary ostium. However, the catheters must be rotated to afford the S-shaped geometry of the subclavian-innominate-aorta axis through the RRA. ${ }^{11,18}$ Less hydrophilic wire use in the LRA may also indicate that the incidence of radial or subclavian tortuosity was lower than that in the RRA. In addition, differ from more time-consume in transradial coronary procedure via LRA for Caucasian, it is not hard for operators to manipulate catheter of left hands by patient's right side owing to smaller body size in Asian. On the basis of these advantages, procedure

Table 4 Vascular complications

\begin{tabular}{|c|c|c|c|}
\hline & $\begin{array}{l}\text { RRA } \\
(n=682)\end{array}$ & $\begin{array}{l}\text { LRA } \\
(n=680)\end{array}$ & $P$-value \\
\hline Radial artery spasm & $25(3.6 \%)$ & $23(3.4 \%)$ & 0.78 \\
\hline Lose of radial artery pulse & $14(2.1 \%)$ & $10(1.5 \%)$ & 0.41 \\
\hline Forearm hematoma & $3(0.4 \%)$ & I (0.I\%) & 0.62 \\
\hline Puncture site bleeding & $13(1.9 \%)$ & II (1.6\%) & 0.69 \\
\hline Arteriovenous fistula & $0(0 \%)$ & $0(0 \%)$ & 1.00 \\
\hline Pseudoaneurysm & $0(0 \%)$ & $0(0 \%)$ & 1.00 \\
\hline Symptomatic stroke & I (0.15\%) & $0(0 \%)$ & 1.00 \\
\hline
\end{tabular}

Note: Data are expressed as number (\%).

Abbreviations: RRA, right radial approach; n, number; LRA, left radial approach. 
duration and fluoroscopy time could be decreased in the LRA compared to the RRA. Therefore, in view of lower subclavian tortuosity, easier catheter manipulation, and less radiation exposure via the LRA, the LRA may be a better and more reasonable choice, and it should be recommended in real-world cardiac catheterization, especially in urgent cases that need a faster coronary procedure.

As for vascular complications, radial artery occlusion and spasm are considered common complications of the transradial approach. ${ }^{19}$ It has been reported that the incidence of radial occlusions was $0.6 \%-1.2 \%,{ }^{20}$ whereas the incidence of a significant loss of radial artery pulse in our study was greater than that of a previous observation. Since we routinely checked the radial artery pulse based on palpation before discharge, the reason for this discordance is that a simple pulse check at the level of radial cannulation is not reliable. Doppler ultrasound should be required to ensure the accuracy of radial occlusion. Radial artery spasms occur in 5\%-10\% of all subjects. ${ }^{21}$ In the present study, the incidence of radial artery spasm was $<3 \%$ in each approach, and it was slightly lower than that in previous investigations. ${ }^{22,23}$ The incidence of forearm hematoma was rare and similar between the LRA and RRA. Only one significant hematoma was observed in the LRA, which was due to radial perforation showing radial contrast extravasation; it was associated with radial tortuosity and hydrophilic wire use. The forearm hematoma resolved without any clinical consequences. Reported cerebrovascular complications were lower than $0.5 \%$ after cardiac catheterization. ${ }^{24}$ In the present study, we found only one case of symptomatic stroke in the RRA group. Aortic arch atheroma is usually considered as a risk factor for embolism during an invasive procedure. ${ }^{25}$ In the RRA, the right subclavian artery arises from the common brachiocephalic trunk and there are two vascular bifurcations at this level. So, this could cause direct embolization into the right common carotid artery when increasing catheter manipulation in the ascending aorta. In addition, longer procedural times and catheter manipulation in or close to the neck vessels have been considered to be associated with an increased risk of both silent and symptomatic strokes. ${ }^{26-28}$ Therefore, special caution is needed for a transradial coronary procedure, particularly in the RRA.

\section{Study limitations}

First, the present study was just a single-center experience, despite the fact that it was also a prospective, randomized study. Larger scale investigations are required to support our findings. Second, randomization was performed only according to the different radial approaches, but not according to the experience of the operators. Third, the CAK dose area product and fluoroscopy time were evaluated only in patients, whereas the radiation dosage to the operator was not measured.

\section{Conclusion}

The LRA seems to be a feasible alternative for coronary angiography in Asian patients, as it is associated with shorter procedure duration and fluoroscopy time, as well as less hydrophilic wire use in comparison to RRA.

\section{Disclosure}

The authors report no conflicts of interest in this work.

\section{References}

1. Archbold RA, Robinson NM, Schilling RJ. Radial artery access for coronary angiography and percutaneous coronary intervention. $B M J$. 2004;329(7463):443-446.

2. Agostoni P, Biondi-Zoccai GG, de Benedictis ML, et al. Radial versus femoral approach for percutaneous coronary diagnostic and interventional procedures; Systematic overview and meta-analysis of randomized trials. J Am Coll Cardiol. 2004;44(2):349-356.

3. Brasselet C, Tassan S, Nazeyrollas P, Hamon M, Metz D. Randomised comparison of femoral versus radial approach for percutaneous coronary intervention using abciximab in acute myocardial infarction: results of the FARMI trial. Heart. 2007;93(12):1556-1561.

4. Pristipino C, Pelliccia F, Granatelli A, et al. Comparison of accessrelated bleeding complications in women versus men undergoing percutaneous coronary catheterization using the radial versus femoral artery. Am J Cardiol. 2007;99(9):1216-1221.

5. Rao SV, Ou FS, Wang TY, et al. Trends in the prevalence and outcomes of radial and femoral approaches to percutaneous coronary intervention: a report from the National Cardiovascular Data Registry. JACC Cardiovasc Interv. 2008;1(4):379-386.

6. Jolly SS, Amlani S, Hamon M, Yusuf S, Mehta SR. Radial versus femoral access for coronary angiography or intervention and the impact on major bleeding and ischemic events: a systematic review and metaanalysis of randomized trials. Am Heart J. 2009;157(1):132-140.

7. Jolly SS, Yusuf S, Cairns J, et al; RIVAL trial group. Radial versus femoral access for coronary angiography and intervention in patients with acute coronary syndromes (RIVAL): a randomised, parallel group, multicentre trial. Lancet. 2011;377(9775):1409-1420.

8. Valgimigli M, Saia F, Guastaroba P, et al; REAL Registry Investigators. Transradial versus transfemoral intervention for acute myocardial infarction: a propensity score-adjusted and -matched analysis from the REAL (REgistro regionale AngiopLastiche dell'Emilia-Romagna) multicenter registry. JACC Cardiovasc Interv. 2012;5(1):23-35.

9. Lo TS, Nolan J, Fountzopoulos E, et al. Radial artery anomaly and its influence on transradial coronary procedural outcome. Heart. 2009;95(5):410-415.

10. Dominici M, Diletti R, Milici C, et al. Left radial versus right radial approach for coronary artery catheterization: a prospective comparison. J Interv Cardiol. 2012;25(2):203-209.

11. Sciahbasi A, Romagnoli E, Burzotta F, et al. Transradial approach (left vs right) and procedural times during percutaneous coronary procedures: TALENT study. Am Heart J. 2011;161(1):172-179.

12. Pelliccia F, Trani C, Biondi-Zoccai GG, et al; Prospective Registry of Vascular Access in Interventions in Lazio Region (PREVAIL) Study Group. Comparison of the feasibility and effectiveness of transradial coronary angiography via right versus left radial artery approaches (from the PREVAIL Study). Am J Cardiol. 2012;110(6): $771-775$. 
13. Kawashima O, Endoh N, Terashima M, et al. Effectiveness of right or left radial approach for coronary angiography. Catheter Cardiovasc Interv. 2004;61(3):333-337.

14. Fernández-Portales J, Valdesuso R, Carreras R, Jiménez-Candil J, Serrador A, Romaní S. [Right versus left radial artery approach for coronary angiography. Differences observed and the learning curve]. Rev Esp Cardiol. 2006;59(10):1071-1074. Spanish.

15. Santas E, Bodí V, Sanchis J, et al. The left radial approach in daily practice. A randomized study comparing femoral and right and left radial approaches. Rev Esp Cardiol. 2009;62(5):482-490.

16. Kanei Y, Nakra NC, Liou M, et al. Randomized comparison of transradial coronary angiography via right or left radial artery approaches. Am J Cardiol. 2011;107(2):195-197.

17. Biondi-Zoccai G, Sciahbasi A, Bodí V, et al. Right versus left radial artery access for coronary procedures: an international collaborative systematic review and meta-analysis including 5 randomized trials and 3210 patients. Int J Cardiol. 2013;166(3):621-626.

18. Sciahbasi A, Romagnoli E, Trani C, et al. Evaluation of the "learning curve" for left and right radial approach during percutaneous coronary procedures. Am J Cardiol. 2011;108(2):185-188.

19. Bhat T, Teli S, Bhat H, et al. Access-site complications and their management during transradial cardiac catheterization. Expert Rev Cardiovasc Ther. 2012;10(5):627-634.

20. Dahm JB, van Buuren F. Transradial percutaneous coronary interventions: indications, success rates and clinical outcome. Indian Heart J. 2010;62(3):218-220.

21. Kiemeneij F. Prevention and management of radial artery spasm. J Invasive Cardiol. 2006;18(4):159-160.
22. Ruiz-Salmerón RJ, Mora R, Masotti M, Betriu A. Assessment of the efficacy of phentolamine to prevent radial artery spasm during cardiac catheterization procedures: a randomized study comparing phentolamine vs. verapamil. Catheter Cardiovasc Interv. 2005;66(2):192-198.

23. Kim SH, Kim EJ, Cheon WS, et al. Comparative study of nicorandil and a spasmolytic cocktail in preventing radial artery spasm during transradial coronary angiography. Int J Cardiol. 2007;120(3):325-330.

24. Segal AZ, Abernethy WB, Palacios IF, BeLue R, Rordorf G. Stroke as a complication of cardiac catheterization: risk factors and clinical features. Neurology. 2001;56(7):975-977.

25. Fuchs S, Stabile E, Kinnaird TD, et al. Stroke complicating percutaneous coronary interventions: incidence, predictors, and prognostic implications. Circulation. 2002;106(1):86-91.

26. Karalis DG, Quinn V, Victor MF, et al. Risk of catheter-related emboli in patients with atherosclerotic debris in the thoracic aorta. Am Heart J. 1996;131(6):1149-1155.

27. Büsing KA, Schulte-Sasse C, Flüchter S, et al. Cerebral infarction: incidence and risk factors after diagnostic and interventional cardiac catheterization - prospective evaluation at diffusion-weighted MR imaging. Radiology. 2005;235(1):177-183.

28. Lund C, Nes RB, Ugelstad TP, et al. Cerebral emboli during left heart catheterization may cause acute brain injury. Eur Heart J. 2005;26(13):1269-1275.
Clinical Interventions in Aging

\section{Publish your work in this journal}

Clinical Interventions in Aging is an international, peer-reviewed journal focusing on evidence-based reports on the value or lack thereof of treatments intended to prevent or delay the onset of maladaptive correlates of aging in human beings. This journal is indexed on PubMed Central, MedLine,

\section{Dovepress}

CAS, Scopus and the Elsevier Bibliographic databases. The manuscript management system is completely online and includes a very quick and fair peer-review system, which is all easy to use. Visit http://www.dovepress. com/testimonials.php to read real quotes from published authors. 